\title{
Ssciendo
}

Ethics \& Bioethics (in Central Europe), 2020, 10 (1-2), 20-29

DOI:10.2478/ebce-2020-0007

\section{To live is to die: A virtue account of arguments for the right to die ${ }^{1}$}

\author{
Franlu Vulliermet ${ }^{2}$
}

\begin{abstract}
In recent years, debates about euthanasia and assisted suicide have increased to the point that now, many people defend the recognition of the right to die, the right for people to decide upon the end of their life. Consistently, advocates fight to legalise practices such as euthanasia to guarantee patients' possibility to die when they request it. In this paper, I review two of the strongest arguments invoked by proponents of physician-assisted suicide: the argument for compassion and the argument for dignity. The focus of this paper is to propose a review of these arguments through the lens of virtue ethics to inform the debate on physician-assisted suicide and question the relevance of such arguments for the legalisation of that right that would greatly ease the possibilities to end the life of a patient asking for it.
\end{abstract}

Keywords: compassion, dignity, right to die, virtue ethics, physician-assisted suicide

\section{Introduction}

Over the past years, debates about euthanasia and assisted suicide have increased to the point that now, many people defend the recognition of the "right to die," the right for people to decide upon the end of their life. Consistently, advocates fight to legalise practices such as euthanasia to guarantee patients' possibility to die when they request it. In this paper, I review two of the strongest arguments invoked by proponents of physician-assisted suicide: the argument for compassion and the argument for dignity. The focus of this paper is to propose a reading of these arguments through the lens of virtue ethics and see how they could inform the debate on physician-assisted death and the relevance of such arguments for the legalisation of that right that would greatly ease the possibilities to end the life of a patient asking for it.

In this article I do not make a differentiation between the two concepts of euthanasia and assisted suicide, following Younger and Kimsma (Younger \& Kimsma, 2012, p. 32) who gather them under the name of physician-assisted death. They define euthanasia as "the unambiguous and intentional ending of a patient's life by a physician" and assisted suicide is when "a physician intentionally provides a patient with the medical means to end his or her life". These active forms of terminating somebody's life are the only ones I consider in this paper, consequently leaving out other possible alternatives such as stopping medical treatments. These active forms are the crux of the dilemma revolving around euthanasia as they imply "directly killing" a patient, as opposed to more passive forms, rather seen as "letting die".

I start by giving a review of two of the most common and powerful arguments advanced by the proponents of the right to die. They invoke the argument of dying with dignity and the argument for compassion to defend their proposal of the right to die, considering this right is consistent with respect for human dignity and that compassion is necessary to benefit people requesting to die. In the second part, I briefly introduce Aristotle's virtue ethics account and the telos of a state, which is to allow people to live a good life and be virtuous. I then examine these two arguments and their meaning in light of Aristotle's concepts to show that according to his demanding approach these arguments do not appear to be sufficient, and only some marginal and extreme cases would justify the possibility of having recourse to physician-assisted death.

\footnotetext{
${ }^{1}$ The paper was presented at the international conference End of Life and Euthanasia - Intersection of Issues and Questions held in Prague (Czech Republic) on 4-5 November 2019.

${ }^{2}$ Linköping University, Linköping (Sweden); fvulliermet@gmail.com
} 


\section{Argument for dignity ${ }^{3}$}

In the debate about euthanasia and assisted suicide, the case of dignity is often invoked: it is one of the most powerful and most common arguments of the proponents of the right to die with dignity (Gentzler, 2003, p. 461). Yet, this argument is problematic. If it has provided a certain unifying normative vocabulary for the debate since people from different professions and different moral strands can refer to human dignity, the term covers nonetheless different meanings and if, to a certain extent, dying with dignity is understood as dying a good death (e.g. a painless death before losing all human capacities), the interpretations of the term are multiple (Gandsman \& Burnier, 2014, p. 2). To make the point clearer, I would sketch out how dignity in its principal meaning is referred to in debates about assisted suicide.

Humans have placed special emphasis on dignity, going as far as to consider they were worthy of a dignity that no other species have. Since this dignity is thought to be the basis of their moral consideration, humans try to preserve it (Gandsman \& Burnier, 2014, pp. 3-4). Even if the concept might be vague or cover different significations, anybody who takes human rights seriously should accept this powerful idea of human dignity (Dworkin, 1977, p. 98). Furthermore, with the development of bioethics during the twentieth century, international organizations have highlighted and put forward the importance of this concept. UNESCO's Universal Declaration on Bioethics and Human Rights (2005) describes humans as having a unique intrinsic value and therefore being worthy of dignity. It seems dignity is of paramount importance for humans, yet we have to clearly define it. That our dignity comes from our intrinsic values stems from Kant, and it is one possible approach of the concept advocates for the right to die have adopted. For Kant, humans have the capacity to act morally. This capacity entitles them to an intrinsic value: because humans have this capacity to act morally, they have dignity (Kant, 2012). As Kant's well-known categorical imperative formulates: "people are ends in themselves" and are not to be treated merely as means for other purposes. As ends in themselves, they shall be considered with utmost respect. Following his definition, suicide is morally impermissible since the one who destroys himself to escape an unbearable situation makes use of his person, reducing it to a mere means to an end. Kant's demanding view does not seem to allow any room to consider the possibility of physician-assisted death (Gentzler, 2003, p. 463). However, many authors have argued on this account about the possibility to commit suicide; arguing along Kant's line of thinking, that there are things worse than death, such as acting immorally. Even if suicide is a moral sin, some situations might require that a person puts an end to their life. Some have tried to prove it (Gentzler, 2003, pp. 464-465) but I will not discuss such views further as I only intend to present Kant's approach of dignity and not to discuss arguments and possibilities of physician-assisted death using his work.

If many retain the idea of dignity being linked to intrinsic value, Kant's view remains abstract and advocates for the right to die usually call for a more practical and contingent understanding of dignity (Gandsman \& Burnier, 2014, p. 5). Dignity is then more subjective; it depends on personal views and how one perceives oneself. From this perspective, dignity is related in terms of suffering, autonomy, and dependency. It is important to understand, that from this perspective, it is not death that is a violation of dignity, but the process of dying. As Gandsman \& Burnier (2014) write, this is the point where the body becomes the source of humiliation, torture, or degradation. People feel ashamed when they lose control and their body falls apart. For instance, if they soil themselves, or if their cognitive functions are damaged to the point they end up being unable to perform any action. As Ackerman emphasized it: "human dignity resides in the bladder and in the rectum" (Ackerman, 1998, p. 151). If the view may sound crude and trivial, many terminally ill patients experience it this way. If humans always depend

\footnotetext{
${ }^{3}$ Here again I make no distinction between euthanasia and assisted suicide, since in the studies about dignity it is not considered (Gandsman \& Burnier, 2014).
} 
in some ways on other beings, as an essential component of human life (Gentzler, 2003), when they must rely on others for their most basic needs, like showering or going to the toilet, this dependency is then perceived as demeaning. Loss of control and dependency are related but distinct: one can depend on somebody because they need help, of a housemaid for instance, but still have control over his or her life.

The emphasis here is on the possibility to have control over life and death: autonomy and self-determination to decide when they happen. Dignity is, in this context, a property we possess as long as we remain in control (Gentzler, 2003). This capacity should not be taken away from people: if someone requests physician-assisted death, ${ }^{4}$ their will shall be executed. If not, this person would lose their dignity at the same time they loses the possibility to choose their death. Kant would have rejected suicide simply based on suffering; however, it is nowadays usually commonly agreed that there is no use to extend the life of somebody who experiences unbearable pain and who has no significant chances of recovery. When the centre of life becomes pain, a person can therefore, lose their dignity. Consequently, respecting this person's dignity might mean putting an end to their life (Velleman, 1999, pp. 617-619). From this second approach, losing dignity is due to one, or a combination of factors a person experiences: unbearable pain, loss of control, or increased dependency (Gentzler, 2003, pp. 466-471). Experiencing terrible pain, being unable to perform the simplest actions in life, or losing total control are, then, the main reasons grounding the argument for a right to die with dignity.

Another way to approach the concept of dignity still within the debate about the end of life was defined by Dworkin in his book Life's dominion. He defines human dignity as the moral right and responsibility to confront the fundamental questions about the value and meaning of our own lives for answering to our own convictions (Dworkin, 1993, p. 166). The ways we reflect on our lives and decide how to act accordingly defines some integrity. There is the integrity of our lives so everything fits in: there is a certain narrative unity in one's life. We envisage pursuing the achievement of a certain character of life through our acts during its course. This is how one can live with human dignity: by making sure of the integrity of their life. The same goes for death: to fits Dworkin's definition of dignity, it should follow the integrity of one's life. From his point of view, most humans protect the integrity of their life and will look for a way to die that will enhance it. Consequently, they shall be entitled to die as they see fit because that would be respecting their dignity.

The approaches of dignity I presented are of course not exhaustive. There are other ways to define dignity. For instance, some link dignity to a religious quality that makes humans special compared to other species because they were made in the image of God (Gandsman \& Burnier, 2014). Nevertheless, the three views I presented are among the most prominent in the debate about physician-assisted death. If they differ on certain points, they start from the same premise: human life has an intrinsic value that should be revered and respected. No matter the definition, dignity remains an ultimate, mandatory, and non-negotiable value (Gandsman \& Burnier, 2014).

\section{Argument for compassion}

Another aspect of granting people the right to die focuses on another value: compassion. The argument considers the good that can be done for the one who is dying: from empathy, the pity we feel for this person, we shall put them out of their misery and help them end their life if it is their wish. In this part, I want to come back to this argument and the virtue(s) advanced to

\footnotetext{
${ }^{4}$ Assuming of course this is a conscience autonomous choice, respecting the criteria established in the country where they reside.
} 
defend the idea that assisted suicide and euthanasia are possible. Namely, it is compassion or pity expressed through the principle of beneficence. ${ }^{5}$

Introducing different accounts of dignity, I present various reasons that could lead to a loss of dignity: increased dependency, loss of control, and unbearable pain. They could also trigger a feeling of empathy and compassion for the close or distant entourage of the patient. This feeling is so strong that it could convince people that the best course of action for the patient is a physician-assisted death to relieve them. ${ }^{6}$ Suffering is widely considered as being intrinsically bad (Sumner, 2011, p. 89) and the normative ethical theory of utilitarianism defines it as the main criterion to determine the morality of an act. From a utilitarian perspective, we shall increase the balance of pleasure over pain and therefore the moral course of action would be to relieve the person suffering. Also, it is important to mention that physician-assisted death is mostly considered for terminally ill patients (see for instance The Oregon Death With Dignity $A c t$ ). Terminally-ill patients have no serious hope of recovery, therefore the pain they experience will lead to no good because it is the suffering they experience during the process of dying (Sumner, 2011, p. 89). From these assessments rises the argument for the well-being of the patient: it is in their interest to prevent them from suffering and help them to die. This is a utilitarian formulation of the argument as it aims at reaching the best outcome, it has the best consequences. However, it can also be formulated in deontological terms as a duty to not inflict unnecessary or avoidable harm (Sumner, 2011, p. 90).

Beauchamp and Childress have integrated such considerations in the four principles they defined, widely used as guidelines throughout the world in biomedical ethics (Beauchamp \& Childress, 2013). One of these principles is the principle of beneficence, which goes along with the principle of non-maleficence. According to Beauchamp and Childress, morality requires that we contribute to people's welfare: we should not only prevent harm from happening to them, but also positively take steps to help them (Beauchamp \& Childress, 2013, p. 202). The principle of beneficence, paired with the principle of autonomy, enables practitioners to express virtues of care and compassion offering by strong reasons to consider the possibilities of physician-assisted death (Beauchamp \& Childress, 2013, p. 185). The feelings and concerns we have for others go beyond rules or principles because they express these virtues and excellence of character. For them, a virtue can be defined as a dispositional trait of character that is reliably present in a person and socially valuable. The moral virtue is not socially, but morally valuable (Beauchamp \& Childress, 2013, p. 31). In the field of health care, they distinguish five virtues as being of paramount importance for professionals because they support and promote good practices in health care. Among these five virtues is compassion (Beauchamp \& Childress, 2013 , p. 33). As I mentioned already, this virtue is triggered by the view of suffering because it focuses on other people's pain and misery. I want to briefly add a clarification here. Usually pity and compassion are used indistinctively as synonyms. Yet, they are slightly different, and I believe that pity would be more accurate than compassion following Beauchamp's and Childress' definition. According to them, this virtue has affinities with mercy and is expressed in acts of beneficence that attempt to alleviate the suffering of another person (Beauchamp \& Childress, 2013, p. 37). Pity can be defined as a feeling of affliction we have for the suffering of others and that drives us to relieve them from it, whereas compassion would rather be the

\footnotetext{
${ }^{5}$ Benevolence can also be considered to be one of the main virtues that could be reintroduced using an Aristotelian approach in the debate about assisted suicide (Zyl, 2000). I do not elaborate much in this paper about the virtue of benevolence, because in this perspective I take benevolence - when it specifically comes to assisted suicide- to be widely influenced by compassion: it provides the motive for being benevolent.

${ }^{6}$ I will leave aside loss of control and dependency. If they could trigger pity, I would need to talk more in detail about it since these two reasons/conditions also presuppose a loss of autonomy, which is fundamental to consider the possibility of assisted suicide (Sumner, 2011) (The Oregon Death With Dignity Act). Even in the case of suffering alone, the first thing to do in case of suicide (intervention) is to determine whether the person acts autonomously or not (Beauchamp \& Childress, 2013, pp. 223-224;184).
} 
feeling that would foster the sharing of this suffering. Etymologically, compassion means 'to suffer with'. Due to the common overlapping definitions of the two concepts that can be found in the literature, I use the two terms indistinctively as synonyms in this paper.

If at first glance the argument for compassion seems to focus on the good that can be done for the patient, it is also powerful because it embodies the expression of compassion, a virtue valuable to society and morality. However, even if the argument for compassion is powerful, the case of assisted death remains problematic. The fact the physician-assisted death aims at the welfare of the patient to relieve their suffering and is motivated by the virtue of compassion is not enough to make it permissible; certain additional conditions must be satisfied to justify it. Many authors have worked on this issue to provide such satisfactory conditions. Beauchamp and Childress distinguish nine different conditions such as an unacceptable suffering by the patient, or a voluntary request by the patient (Beauchamp \& Childress, 2013, p. 184). In comparison Sumner lists only five criteria, although he also stresses the importance of unbearable pain and a careful assessment of the patient (Sumner, 2011, pp. 90-91).

\section{Virtue ethics ${ }^{7}$}

Although tracing back to Aristotle and Plato, virtue ethics remained marginal for centuries, to be revived in the 1950s by the British philosopher Anscombe when deontological and utilitarian arguments were unsatisfactory. It was first and foremost conceptualized in Aristotle's works. In Nicomachean Ethics, Aristotle defines what it is to live a good life by eudaimonia; happiness, better understood as human flourishing. It is the supreme end humans should pursue. To do so, humans must develop their virtues, moral character traits that will enable them to achieve this eudaimonia, because it is not merely a life of pleasures that will procure happiness in different ways to each human, but the ultimate end of the exercise of their virtues. Then, to be good, one must have been well-raised, to have developed good habits and live following them by behaving honestly (Aristotle, 2004b, I, 4). For being virtuous, one must practise developing one's character traits. Having a virtue means to be a certain person with a complex mind-set: mainly the acceptance of a certain range of considerations as a reason for action (Hursthouse, 2013). For Aristotle, possessing a virtue is a matter of degree; it is a decisional state, the middle of which is anchored in us. The middle between two vices; one of excess and the other of deficiency (Aristotle, 2004b, VI, 1). I think it is important to mention that being virtuous is a hard achievement, and as Athanassoulis (2000) mentions, the number of ways to fall short is many. For instance, a way to fall short would be due to a lack of moral or practical wisdom (phronesis). As I mentioned before, to be virtuous, one must make the best use of one's virtues and reason in one's life to achieve eudaimonia. And to do so, one must also have this knowledge or understanding that will enable one to do just that. Without this knowledge, one cannot be said to be truly virtuous. For instance, a child might be nice or honest because of his naivety and innocence but because he lacks phronesis, this knowledge, he cannot be virtuous in Aristotle's conception.

Now in light of this discussion, I shall briefly introduce the role of the state, the role of politics. According to Aristotle, the state exists for the sake of the good life and not merely life only (Aristotle, 2000, III, 9). It aims at cultivating the virtues of the citizens; that is the role of the state. Aristotle discusses different possible forms of government and the virtues of their citizens. He also discusses the possible differences of virtues between the good man and the citizen; in some states they are alike, in some they differ. However, in the perfect state, the virtues of the citizen and the virtues of the good man are the same (Aristotle, 2000, III, 4). In these conditions, the state then aims at developing the virtue of people to allow them, to become truly good. A variety of governments exist today. While it is beyond the scope of this article to

\footnotetext{
${ }^{7}$ I limit myself to the traditional view as defined by Aristotle.
} 
argue for one over another and determine which form would be the most appropriate to realize the envisioned goal, beyond practical considerations, I take the stance that the telos of a state remains, in line with Aristotle to allow its people to be good humans and citizens, no matter which forms it may take. The good citizen is an important part because according to Aristotle, the political association would be nothing more than a mere alliance. But I focus here on the good man who shall pursue his telos and develop his virtues through good habits and practical wisdom to achieve eudaimonia. The state should therefore encourage people to do so and create a propitious environment where they would have the possibility to develop their virtues. It is with these considerations in mind that we shall approach and reflect on the topic of physicianassisted death and see whether or not it allows and encourages people to develop their virtues. With this teleological perspective in mind, I now discuss the two arguments for compassion and dignity and consider how they fit this conception.

\section{Discussion}

While discussing the concept of dignity, I highlighted its importance from different approaches. I have also explained that we often refer not only to dignity but to human dignity, in a way that we would have our very own special value. Compared to other living beings, we have dignity they do not, and if not superior, it implies nonetheless that we are different from plants and animals. But what sets us apart from these beings? According to Aristotle, the potential we have for cognitive and emotional capabilities sets us apart from them, it makes one human (Aristotle 2004a, II). Introducing virtue ethics, I presented the idea that the telos of human beings was to achieve eudaimonia by the exercise of their virtues. This is possible thanks to their capabilities: the cognitive and emotional capabilities that allow a human to live a good, distinctively human life are virtues (Gentzler, 2003). Hence, they are not valuable from an instrumental perspective; we do not merely use them to satisfy our basic needs, but to achieve a good life. From an Aristotelian perspective, this is how human dignity is possible. It comes from our unique capabilities and the use we make of them. It is thus possible to make a parallel between his understanding of dignity, and the second and third accounts I gave. To make use of these capacities, humans need certain levels of independence and control. To fulfil the purpose of achieving a good life they will have to make extensive use of these capabilities such as problemsolving, or certain control over feelings such as fear, or desire (Gentzler, 2003). Intuitively, such a virtuous account of human dignity would also seem to fit Dworkin's integrity of one's life, with the exception that the narrative unity in Aristotle's virtue ethics cannot be just any. It is clearly defined; it is eudaimonia. The same way Dworkin explained a death with dignity as one that fits the integrity of the person's life, a death with dignity according to Aristotle is consistent with a life lived with dignity. Nussbaum in her capability approach has developed a concept of dignity following Aristotle's lines. For her, this human dignity is inalienable and comes from humans' capacities for various actions and striving (Nussbaum, 2008, chapter 14). According to Nussbaum, respecting this human dignity means creating favourable conditions for development, which is consistent with the role of a state as I introduced it: to create a favourable environment allowing people to achieve a good life. It is the responsibility of the state and the society through its basic structure to ensure that conditions are reunited so it is possible for a human to live with dignity (Nussbaum, 2008, chapter 14).

Should a state enact a law in favour of the right to die to then allow the practice of physicianassisted death? For Aristotle, the law forbids suicide, and thus the one who commits it acts unjustly (Aristotle, 2004b, V, 11). Such person acts against right reason, she acts unjustly, not to herself, but to the state. Can the consideration and esteem we have for dignity turn the tables? Carefully considering the argument for dignity, a person may have the possibility to die when they cannot live their life with dignity anymore. Along the lines of virtue ethics we have discussed so far, it would entail that this person cannot make use of the capabilities allowing 
them to achieve eudaimonia. People in a vegetative state for instance with no hope of recovery may fit such a description. Yet, this implies that we have already reached a stage where we examine cases of people finding themselves in extremely severe irremediable living conditions, and for whom considering the state's telos has no reason of being anymore.

But before reaching such an extent, and considering the possibility of physician-assisted death to give people the possibility to terminate their life, a state should rather consider the needs of its people at different stages in their life, and act in accordance to do everything so they could live with dignity before examining the possibility of a right to die. In other words, for people who might consider the option of terminating their lives, from a virtuous perspective, the most important question to ask normatively speaking, would not be whether granting these people such a possibility is right or wrong. The fundamental consideration would be whether or not there are any possibilities left for these people to live with dignity. For this point, the case of Jean-Dominique Bauby can serve as a brilliant illustration. Bauby was a very successful family man, and acclaimed journalist in his mid-forties. One day he had a stroke. After weeks in a coma, he woke up suffering from locked-in syndrome; while his cognitive capacities remained intact, he could only move his left eyelid; the rest of his body remained paralyzed. Life as he had known it was forever over. Yet, he did not give up and kept communicating with the people around him, by blinking, dictating his words, letter, after letter. Rather than seeking relief in death, Bauby told his story in a book he wrote by dint of hard work only using his left eyelid. Now, it would seem very odd to me, and quite obnoxious to consider that he has not lived in dignity, for he who has remained resilient and courageous facing such a desperate situation. Undoubtedly, I recognize the strength of will Bauby has shown is unique. He may very well be an exception, and not all patients in the same dire conditions may be able to respond the way he did, and such dramatic stories rightly compel us to question whether for Bauby, and patients in similar conditions, ending life could not be the best option. Some trains of thought may reach this conclusion. However, for virtue ethics, the state's telos is to allow us to live our life with dignity, even when everything seems lost, and to inspire us to walk in Bauby's footsteps. As Nussbaum said, the sheer fact of prolonging life is good and should be encouraged, and whichever our condition may be, we should seek to live in dignity above all. Only in cases where we have exhausted all possibilities and there is effectively no real possibility to live with dignity, the option of a death with dignity should be considered (Nussbaum, 2008, chapter 4).

Going further, the purpose of physicians and people working in healthcare is the safeguarding of life. All the more so referring to the original Hippocratic Oath. I believe this should be encouraged till to the point where achieving a life with dignity becomes truly impossible when life has nothing human anymore. Should this possibility be granted to everyone? In my opinion, the state should not enact a law in favour of physician-assisted death. As I intended to explain, physician-assisted suicide is a last resort measure that should be possible in some marginal cases. However, if it be possible and permissible, the state should not encourage its citizens, in any manner, to have recourse to ways of terminating their life through a law that would recognize one's possibility to take one's own life. From this analysis, the argument of dignity falls short of legitimising the right to die allowing people to decide upon their death.

Aristotle seems particularly relevant when discussing the second argument invoked by the proponents of the right to die. His definition of compassion fits our modern understanding of it. Aristotle sees compassion ${ }^{8}$ as a feeling of pain caused by the sight of destructive or painful evil which befalls one who does not deserve it and which we might expect to befall us (Aristotle, 1991, II, 8). The description he makes of plights susceptible to spark compassion is also relevant

\footnotetext{
${ }^{8}$ Aristotle uses the term 'pity' in his work, but as I mentioned due to the overlapping uses of the terms in literature, I use pity and compassion as synonyms.
} 
for our case. He evokes the most terrible evils of human life: death, bodily injuries, old age, afflictions, or diseases. They all are susceptible to stimulate pity. Considering the occurrences of these evils in the lives of physicians and healthcare personnel, it seems evident the importance of empathy and compassion considered as a virtue as Beauchamp and Childress developed it. It allows physicians to understand the way patients feel, and their state of mind to better benefit them, and serves as a driving force to relieve them. Yet, the question is whether Aristotle thought about compassion as a virtue or not and if it should be developed by the good man. The answer is not evident. Aristotle primarily sees pity as a feeling, yet he recognizes it is associated with good moral character (Aristotle, 1991, II, 1) and for this reason can be considered a virtue. I presented Aristotle's approach to virtue as a mean between two extremes: one of excess and the other of deficiency. Compassion despite being a virtue can also be a fault: someone's compassion can lead them to tell lies or act immorally. A compassionate person displays a virtuous character when they feels pity for the right reasons, the right people, and in the right ways, which would be to act appropriately in our case where we look at compassion and its practical implications. Defining pity, Aristotle presents the necessity of three judgments for the onlooker to form compassion: the judgment that the pain is serious and not trivial, the judgment that the pain is undeserved, and the judgment that a person may find himself in the same circumstances, going through the same pain as the person who is suffering. If for any reason, like cognitive impairment, one or more of these judgments is mistaken, it would result in unwarranted compassion. It follows that compassion is not necessarily a virtue, and needs further specification. Being compassionate for someone who has deserved the evils that have befallen them would be an excess of compassion and maybe not the expression of a truly virtuous character. There are cases of physicians who euthanized their patients invoking compassion, because they genuinely wanted to put them out their misery, thinking they did not have any chance of survival. Compassion can not only be the only criterion in such cases, and it must be carefully assessed, so it is beneficial and truly the expression of a virtuous character in line with regulations, at the risk of leading to harmful actions and disastrous consequences. It would be a long discussion to clarify which evils are deserved or not, to say that being compassionate is appropriate in certain defined cases of assisted death or not, and determine more precisely the validity of the argument. My purpose was to show that compassion is positively perceived and valued by society. It may be considered as a critical virtue healthcare personnel should foster, however, a thorough assessment of compassion in light of virtue ethics indicates that it is not as straightforward as it seems, and limitations of this understanding of the term appear.

Furthermore, the argument could somehow seem distorted, that, by, let's say, granting the right to die allow physicians to express a virtuous compassionate character and benefit patients, there would be no other possibility for physicians to do so. Yet, physicians can be compassionate and benefit their patients in other ways, by providing pain relief or mental support for instance. It does not entail that by not granting the right to die, the state prevents physicians from developing their virtuous character. As for Aristotle and virtue ethics, telos is the normative relevant criterion, neither the argument for compassion overrules the argument for dignity, nor does it prevent the achievement of the state's or physicians' purpose. Following the same logic, only in the most severe cases where a physician would have no other ways left to benefit the patient or to express its virtuous character, and within limits previously mentioned, would the argument for compassion be consistent with virtue ethics. But when such cases arise where physician-assisted death is requested, some practitioners should be ready to do it, out of compassion. Bear in mind that I, again, do not say that society should encourage it and that the argument is convincing enough to justify the recognition of the right to die: following the remark I made discussing dignity, if we do not encourage people to have recourse to physician-assisted death, we may want this option to be possible and remain exceptionally 
permissible in some cases. In the eventuality of such cases, we need physicians who would be ready to do it. Here again, the role of the state would be to create this propitious environment where a virtuous character can express itself out of compassion and in the execution of physician-assisted death in cases that require it. This goes along with the careful assessment that the conditions are reunited and it is compassion as a virtue that is expressed.

\section{Objections and conclusion}

I would conclude this paper by addressing some possible objections to the points I have made. One possible objection to the first argument is the possibility to live a life without dignity. If there is a consensus on the value of living with dignity and everyone arguably pursues this goal, following the approaches I introduced, living a life with dignity is demanding. Some people may lack abilities or cognitive capacities making it thus impossible for them to achieve it. Crippled war veterans losing the functioning of their body, or people born with mental impairment such as autism may not be fit for it, especially if dignity is conceived in terms of functioning or capacities. Some might imply that the life of these people is therefore not worth living. I simply reject the idea that a life worth living requires dignity. It does not mean such lives are meaningless, or that these people cannot get some sense of pleasure or enjoyment, or they cannot live following principles. In the same spirit, one's dignity being violated does not warrant the termination of one's life.

Another possible objection concerns compassion and the requirements I formulated. They may appear too demanding and impractical; it seems unrealistic to ask practitioners to feel compassion only under certain circumstances. It is perfectly acceptable to feel compassionate; society values it and it can bring valuable information to reflections about assisted death. I simply highlight again, that in a practical approach, when it comes to a critical topic such as ending a person's life, understanding and framing compassion, not only as an emotion but as a virtue, as Aristotle defined, could be an effective safeguard against negative consequences that could arise from acts taken upon the willingness to be compassionate. Being compassionate is perfectly acceptable in any situation so to speak, but if one acts out of compassion, it should be for the right reasons, the right people, and in the right ways.

Starting from the consideration of two of the main arguments invoked by proponents of the right to die, I introduced virtue ethics as conceptualized by Aristotle to show that the telos of a state is not to encourage its citizens to engage in behaviours threatening their life. A state should rather work to enable its citizens to develop and exercise their virtues to live a life with dignity achieving eudaimonia. Only when there are no possibilities for a person to live a life with dignity, the possibility of physician-assisted death should be considered. I do not believe the arguments for dignity and compassion are strong enough to justify the enactment of the right to die and the subsequent laws allowing it. Nevertheless, I recognize that assisted death may in some cases be an appropriate solution and should be possible and permissible. The two arguments would still stand by fulfilling the demanding conditions in these cases, allowing, then, the possibility of this last resort option to end a person's life. In these marginal cases, where the arguments of compassion and dignity would be consistent with virtue ethics as presented, they are not sufficient to justify the recognition of the right to die.

\section{References}

ACKERMAN, F. (1998): Assisted suicide, terminal illness, severe disability, and the double standard. In: M. P. Battin, R. Rhodes \& A. Silvers (eds.): Physician-assisted suicide: Expanding the debate. New York: Routledge, pp. 149-162.

ARISTOTLE (1991): The art of rhetoric. London: Penguin Classics.

ARISTOTLE (2000): Politics. London: Penguin.

ARISTOTLE (2004a): De Anima (On the Soul). London: Penguin. 
ARISTOTLE (2004b): The Nicomachean ethics. London: Penguin Classics.

ATHANASSOULIS, N. (2000): A Response to Harman: Virtue ethics and character traits. In: Proceedings of the Aristotelian Society, 100(1), pp. 215-221.

AUTHORITY, O. H. (n.d.). The Oregon Death With Dignity Act-Statute. [online] [Retrieved February 5, 2020] Available at: https://www.oregon.gov/oha/PH/PROVIDERPARTNERRES OURCES/EVALUATIONRESEARCH/DEATHWITHDIGNITYACT/Pages/ors.aspx.

BEAUCHAMP, T. \& CHILDRESS, J. (2013): Principles of biomedical ethics. New York: Oxford University Press.

DWORKIN, R. (1977): Taking rights seriously. Cambridge: Harvard University Press.

DWORKIN, R. (1993): Life's dominion. New York: Knopf.

GANDSMAN, A. \& BURNIER, D. (2014): "Can't you at least die with a little dignity?" The Right to Die. In: Bioéthique Online, 3(8), [online] [Retrieved February 5, 2020] Available at: https://papyrus.bib.umontreal.ca/xmlui/handle/1866/10945

GENTZLER, J. (2003): What is a death with dignity? In: Journal of Medicine and Philosophy, 28(4), pp. 461-487.

HURSTHOUSE, R. (2013): Virtue ethics. [online] [Retrieved February 5, 2020] Available at: http://plato.stanford.edu/archives/fall2013/entries/ethics-virtue/

KANT, I. (2012): Groundwork of the metaphysics of morals. Cambridge: Cambridge University Press.

NUSSBAUM, M. (2008): Human dignity and political entitlements. In: A. Schulman (ed.): Human dignity and bioethics: Essays commissioned by President's Council on Bioethics. Washington: President's Council on Bioethics, pp. 351-380.

SUMNER, L. W. (2011): Assisted death: A study in ethics \& law. Oxford: Oxford University Press.

VELLEMAN, J. (1999): A right to self-termination? In: Ethics, 109(3), pp. 606-628.

YOUNGER, S. \& KIMSMA, G. (2012): Physician-assisted death in perspective. Cambridge: Cambridge University Press.

ZYL, L. v. (2000): Death and compassion: A virtue-based approach to euthanasia. Farnham: Ashgate. 